\title{
PERCEPÇÕES DA COMUNIDADE ESCOLAR SOBRE OS RESULTADOS QUALITATIVOS E QUANTITATIVOS EM UMA ESCOLA INTEGRAL
}

\author{
ALESSANDRA MARCOS AGUIAR \\ Universidade de Pernambuco (UPE). Mestre em Educação pela Universidade de \\ Pernambuco. Professora da Secretaria de Educação e Esportes do estado de Pernambuco. \\ ORCID: 0000-0003-2232-8704. E-mail: alessandramarcos10@hotmail.com

\section{ODALÉA FEITOSA VIDAL} \\ Universidade de Pernambuco (UPE). Doutora em Educação pela UFAL. Professora Adjunta na \\ Universidade de Pernambuco. ORCID: 0000-0002-6759-0784. E-mail: odalea.vidal@upe.br
}




\section{PERCEPÇÕES DA COMUNIDADE ESCOLAR SOBRE OS RESULTADOS QUALITATIVOS E QUANTITATIVOS EM UMA ESCOLA INTEGRAL}

O objetivo deste artigo é perceber, a partir da escuta da comunidade escolar, os impactos dos resultados obtidos por uma escola integral do município de Surubim, no estado de Pernambuco. Para tanto, procedeuse a uma pesquisa quali-quantitativa, por meio de aplicação de questionários estruturados. A metodologia norteou-se pela pesquisa-ação, com dados obtidos por um grupo focal. Percebeu-se, o reconhecimento da comunidade escolar sobre o papel da gestão na oferta de um ensino com qualidade social, por meio de variados projetos pedagógicos. Espera-se que os achados desta investigação possam inspirar outras escolas integrais, a fim de enriquecer sua rotina escolar com ações significativas e fomentadoras de protagonismo.

Palavras-chave: Educação Integral. Comunidade Escolar. Projetos Pedagógicos.

\section{SCHOOL COMMUNITY PERCEPTIONS ABOUT QUALITATIVE AND QUANTITATIVE RESULTS IN AN INTEGRAL SCHOOL}

The objective of this article is to understand, from the listening of the school community, the impacts of the results obtained by an integral school in the municipality of Surubim, in the state of Pernambuco. Therefore, a qualitative and quantitative research was carried out, using structured questionnaires. The methodology was guided by the action research approach, with data obtained from a focus group. It was noticed the recognition of the school community on the role of school management in offering a teaching with social quality, through several pedagogical projects. It is expected that the findings of this investigation may inspire other integral schools, in order to enrich their routine with actions and protagonism promotion.

Keywords: Integral Education. School Community. Pedagogical Projects.

\section{PERCEPCIONES DE LA COMUNIDAD ESCOLAR SOBRE LOS RESULTADOS CUALITATIVOS Y CUANTITATIVOS EN UNA ESCUELA INTEGRAL}

El objetivo de este artículo es comprender, a partir de la escucha de la comunidad escolar, los impactos de los resultados obtenidos por una escuela integral en el municipio de Surubim, ne el estado de Pernambuco. Para esto, se realizó una investigación cualitativa y cuantitativa, mediante la aplicación de cuestionarios estructurados. La metodología fue guiada por la investigación-acción, con datos obtenidos por un grupo focal. Se notó el reconocimiento de la comunidad escolar sobre el papel de la gerencia en ofrecer una enseñanza con calidad social, a través de diversos proyectos pedagógicos. Se espera que los resultados de esta investigación puedan inspirar a otras escuelas integrales, a fin de enriquecer su rutina escolar con acciones significativas que promuevan el protagonismo.

Palabras clave: Educación Integral. Comunidad Escolar. Proyectos pedagógicos. 


\section{PERCEPÇÕES DA COMUNIDADE ESCOLAR SOBRE OS RESULTADOS QUALITATIVOS E QUANTITATIVOS EM UMA ESCOLA INTEGRAL}

\section{Introdução}

As atividades pedagógicas desenvolvidas no chão da escola demonstram ter relevância, quando promovem a emancipação e protagonismo dos estudantes. Promovendo vivências reais, que os preparem para sua atuação na sociedade, quer seja por meio das futuras práticas acadêmicas, ou no mundo do trabalho. No entanto, esta contribuição dos educadores na vida do jovem, precisa ser acompanhada por toda a comunidade escolar, pois é a partir dessa cooperação que serão obtidos resultados qualitativos e quantitativos na instituição escolar.

O presente artigo tem como objetivo, perceber, a partir da escuta da comunidade escolar, os impactos dos resultados obtidos por uma escola integral do município de Surubim, Pernambuco. Além disso, serão apresentados os desafios da escola integral, as vozes da comunidade, através da perspectiva da pedagogia de projetos.

Para tanto, utilizou-se em sua metodologia, o tipo de pesquisa exploratória, que através de métodos qualitativos proporcionará o levantamento de informações, a construção de hipóteses, a familiaridade com os objetos teóricos e empíricos, bem como com a questão geradora, o que levou a uma coleta de dados que serviu de base para análise e resultado final do trabalho. Foram analisados, ainda gráficos informativos e resultados de instrumentos como questionários.

A participação efetiva da comunidade escolar nas decisões da escola tem sido bastante evidenciada nos últimos anos, quando se tem dado maior atenção à valorização dos órgãos colegiados e representações estudantis. É devido a esse feedback que as escolas têm avançado na questão da gestão democrática.

De acordo com Röhr (2013), como orientação para a reflexão pedagógica, não podemos nos basear apenas em referências externas. Devemos nos fundamentar na integralidade do ser humano, levando em conta todas as suas dimensões, embora saibamos que a influência de fatores externos também interfere no seu processo educativo.

\section{plurais}


Ainda segundo este autor, a educação é um ato político. É a partir da conquista das novas gerações que se procura o domínio da situação, a perpetuação de domínios políticos, a divulgação de credos e a imposição de interesses econômicos. Nesse sentido a educação acaba se tornando serva desses interesses e satisfações político-sociais, envolvendo seus agentes no fortalecimento de sua perpetuação. Como agentes aqui, entendemos todos os envolvidos no processo educativo: profissionais da educação, estudantes etc.

Em uma escola integral, investe-se na formação do ser, tomando por base os princípios norteadores da Educação Interdimensional, que enfatizam o protagonismo juvenil e o desenvolvimento das dimensões do ser humano: Logos, Mytho, Pathos e Eros, buscando ainda no dia-a-dia estar pautados nos pilares da educação: Aprender a Conhecer, Aprender a Fazer, Aprender a Conviver, Aprender a Ser (DELORS, 2010).

Embora o foco seja no aspecto pedagógico, outros necessitam estar a serviço do bem-estar do jovem estudante, que por sua vez necessita de condições mínimas para o desenvolvimento cognitivo favorável. A partir desta necessidade, uma escola de referência em ensino médio (EREM) deve buscar desenvolver no seu dia-a-dia, atividades diversas que além de garantir o cumprimento da carga horária e a grade curricular, deve também proporcionar momentos de interação, descontração, reflexão, protagonismo e convivência.

Especialmente através do protagonismo juvenil, o jovem é convidado a programar, articular, realizar, ser avaliado e recompensado por atividades que constituem o calendário cultural da escola e projetos diversos, como os citados anteriormente.

\section{A escola integral e seus desafios}

As conquistas diárias, realizadas por gestão, docentes e funcionários representam um ganho enorme na função social da escola. Os resultados colhidos em cada ação feita na coletividade, demonstram o quanto temos avançado. No entanto, uma escola em tempo integral não possui apenas aspectos positivos, que levam os estudantes a melhores resultados. Há uma série de desafios diários, de toda ordem, que por vezes impedem a consecução de certas tarefas.

A escola em tempo integral, oferece aos jovens uma realidade bem distinta daquela conhecida por eles na escola regular. A começar pela permanência diária em tempo integral, bastante 
cansativa, eles ainda se deparam com diferenciais como: um aumento considerável no quantitativo de disciplinas, o novo sistema de avaliação, que inclui semanas de exames, semanas de simulados, datas determinadas para segundas oportunidades, devidamente justificadas e solicitadas em tempo hábil, aceitação de refeições padronizadas, servidas por firmas terceirizadas, foco em avaliações externas, maior cobrança em relação a cumprimento de horários, respeito às normas de convivência, resultados a serem atingidos, entre outras.

Não parece ser fácil, pertencer a uma escola com este funcionamento, especialmente se durante o ensino fundamental não tiveram nenhum conhecimento e muito menos vivência deste sistema. Por este motivo, é necessário por parte dos profissionais de escolas em tempo integral: professores, funcionários de limpeza, alimentação, segurança, administrativo disciplina e equipe gestora; garantir o bem-estar, a atenção e toda a gama de subsídios necessários à permanência prazerosa deste jovem no ambiente escolar e sua formação interdimensional.

Há de se considerar, então, que os jovens inseridos no espaço escolar têm suas vivências e experiências nesse espaço e é nele que também terão, ao menos em parte, sua subjetividade constituída a partir das, e nas relações que aí estabelece com seus pares - os colegas, professores, coordenadores; enfim, é nessa rede de relações mantidas com os outros sujeitos que ele se constituirá como sujeito social, bem como construirá sua singularidade. (MANCINI, 2006, p.62).

De acordo com este autor, é a partir das relações estabelecidas e vivenciadas no dia a dia da escola, com as pessoas que a compõem, que o jovem estará construindo as suas características, suas especificidades, características estas que definirão este jovem enquanto ser individual que convive em sociedade. Ou seja, é neste espaço de convivência e aprendizagem que o jovem construirá sua identidade como cidadão.

É fato que a escola em tempo integral requer uma adequação e investimentos constantes de forma que possa oferecer ao estudante, o mínimo de condições possíveis que possibilite seu bemestar, uma vez que passa na escola o dia inteiro, todos os cinco dias úteis da semana. Isso significa entre outras coisas: transporte escolar garantido, espaços adequados, recursos humanos suficientes e preparados para lidar com esta clientela, acesso a internet, alimentação balanceada e de qualidade, acompanhamento e atenção voltados para o desenvolvimento de suas habilidades e até mesmo auxílio pessoal, podendo suprir assim suas necessidades físicas, sociais, intelectuais e emocionais.

\section{plurais}


De acordo com as dificuldades financeiras pelas quais atravessa o nosso país atualmente, torna-se cada vez mais difícil atender a estas exigências. Além disso, se faz necessária também certa disponibilidade da família para acompanhar todo o processo de desenvolvimento destes estudantes, apoiando a escola de maneira que juntas, escola e família, possam exercer suas funções no processo de desenvolvimento de cada um. Como afirma Piaget (2007):

Uma ligação estreita e continuada entre os professores e os pais leva, pois a muita coisa que a uma informação mútua: este intercâmbio acaba resultando em ajuda recíproca e, frequentemente, em aperfeiçoamento real dos métodos. Ao aproximar a escola da vida ou das preocupações profissionais dos pais, e ao proporcionar, reciprocamente, aos pais um interesse pelas coisas da escola chega-se até mesmo a uma divisão de responsabilidades. [...] (PIAGET, 2007, p.50)

A escola deve preocupar-se ainda em proporcionar momentos de interação entre ela e a família, de forma que os pais e/ou responsáveis, apesar de suas próprias dificuldades, sintam-se partícipes no trabalho que a escola desenvolve na formação de seus filhos, o quanto sua presença é necessária para a construção deste cidadão que tem como formação inicial a própria família. A escola oferece a educação sistemática, porém formação principal se dá na corresponsabilidade com a família.

A formação continuada dos professores e a presença pedagógica de todos os profissionais da escola é outro fator de suma importância e responsabilidade para o bom funcionamento e resultados numa escola de tempo integral. Pereira (2011, p. 69), destaca que:

A docência, portanto, é uma atividade complexa porque a realidade na qual o professor atua é dinâmica, conflituosa, imprevisível e apresenta problemas singulares que, portanto, exigem soluções particulares. Exige mobilizações de saberes para o cumprimento do objetivo de educar que é: o desenvolvimento das diferentes capacidades - cognitivas, afetivas, físicas, éticas, estéticas, de inserção social e de relação interpessoal - dos educandos, que se efetiva pela construção de conhecimentos.

Esta citação aponta para a necessidade de uma melhor atuação escolar, mais especificamente com a escola em tempo integral, pois, de acordo com o que vimos, refere-se não apenas à formação no sentido pedagógico, cognitivo, mas aos aspectos enfatizados neste modelo de escola em relação às dimensões do ser: racional, espiritual, afetiva e corpórea. Além de referir-se também a 
aspectos relacionados a relações interpessoais, uma das maiores preocupações do corpo docente e da equipe gestora desse modelo de escola, especialmente no $1^{\circ}$ ano, quando o (a) estudante novato (a) enfrenta diversas mudanças no seu novo ambiente, cotidiano e contatos com pessoas diferentes, vindas também de diferentes realidades.

Mediante todos esses aspectos, podemos perceber um pouco da complexidade e dos desafios de estar à frente de uma instituição de ensino integral.

De acordo com Dourado, Oliveira, Santos (2007), a organização da escola precisa contribuir para a qualidade da educação, valorizando os sujeitos envolvidos no processo, os aspectos pedagógicos, as expectativas dos envolvidos com relação a aquisição dos saberes escolares significativos e às diferentes possibilidades de trajetórias profissionais futuras.

Sendo assim, de forma a garantir uma educação de qualidade, pautada nos princípios de gestão democrática, deve-se perpassar pela articulação entre as atividades administrativas e pedagógicas e priorizar a participação e o envolvimento de todos os sujeitos que compõem o processo de ensino e aprendizagem.

Torna-se importante analisar uma das premissas interdimensionais: A Pedagogia da Presença. De acordo com Costa (2001, p. 26): "Esta é uma postura que exige de quem educa, uma clara noção do processo e uma ágil inteligência do instante, implicando a necessidade de combinar, de forma sensata, uma boa dose de senso prático com uma apreciável veia teórica”. É claro que o professor é a figura que possui contato mais direto com os estudantes e por isso mesmo possui mais condições de representar esta presença na vida dos mesmos, conhecer suas histórias de vida que refletem muitas vezes em seus comportamentos, relacionamentos e resultados.

Não podemos esquecer, porém, que estamos nos referindo a uma escola de funcionamento em horário integral, onde todos os funcionários passam os cinco dias da semana, de manhã à tarde, convivendo com estes estudantes, como os quais acabam tendo, às vezes, mais contato do que com os próprios familiares. Sendo assim, é preciso muito cuidado, atenção e providência no sentido de significar presença marcante positiva, apoio e exemplo para estes jovens. Afinal, somos todos educadores, temos um compromisso com a formação de cada estudante, seja ela nos aspectos: intelectual, corporal, espiritual e afetivo.

\section{plurais}


Em relação ao gestor escolar este deve ser um mediador de todos os aspectos que compõem o processo de ensino e aprendizagem: o pedagógico, o administrativo, o relacional, dando ênfase à participação de todos no sentido de desenvolver uma gestão democrática, voltada para os interesses da comunidade em consonância com a realidade na qual está inserida.

É importante ressaltar que o ensino médio é a fase em que, além de estar aprofundando os conhecimentos obtidos no ensino fundamental, o jovem estará vivendo a fase da adolescência, talvez a mais crítica do ser humano, também é a fase em que ele se encontra a definir sua trajetória de vida e de trabalho.

Considerando-se que seja um grande desafio para a família e para o estado garantir formação educativa no ensino médio, muito mais educação em tempo integral. Sendo assim, esta proposta apresenta diversos tipos de dificuldades e desafios que requerem uma atenção e providências específicas para sua efetivação com qualidade. Sobre isto Krawczyk (2013) afirma que:

Essas mudanças no sistema educacional brasileiro são de extrema importância, porque conferem à educação média o estatuto de direito de todo cidadão. Mas, não é uma tarefa fácil a definição de políticas para esse nível de ensino em razão da falta de consenso sobre sua função social, pois o processo de expansão gera novos desafios para a comunidade educativa: é preciso criar condições institucionais e de aprendizagem em sintonia com o mundo contemporâneo para toda a população e, principalmente, faz-se necessária uma cultura social democrática que tenha como princípio de qualidade a inclusão de todos nossos jovens numa relação significativa com a escola. (KRAWCZYK, 2013, p. 3)

Diante deste contexto, é importante salientar que o país vive hoje uma crise socioeconômica crítica, e a educação, que deveria ser uma das prioridades para o pleno desenvolvimento da cidadania, também se encontra neste estado de mudanças e incertezas. É certo que o número de escolas em tempo integral vem aumentando, porém também é correto afirmar que o modelo brasileiro de infraestrutura e manutenção dessas escolas, deixa muito a desejar, assim como a organização e o funcionamento do currículo, especialmente se considerarmos o mundo contemporâneo e as necessidades de nossos jovens.

Talvez o problema esteja no fato de que, simplesmente importar um modelo de escola de outros países que possuem realidades totalmente diferentes da nossa, sem levar em conta essas diferenças, não seja a solução para que tenhamos nossas necessidades atendidas de forma satisfatória. 
Sander (2015) torna-se ainda mais específico e objetivo em relação ao funcionamento das escolas de ensino médio em tempo integral quando afirma:

A integração da cultura ao mundo da ciência e do trabalho é exigência fundamental de uma concepção unitária e integral de educação básica. As atividades culturais e lúdicas são fatores determinantes da formação para a cidadania e a convivência social de crianças e adolescentes, jovens e adultos. Este fato torna-se um elemento adicional em favor da escola em tempo integral, no sentido de que ela permite reservar tempo e espaço para o desenvolvimento do talento cultural e artístico e da atividade esportiva, elementos constitutivos da qualidade de vida humana em sociedade. Este posicionamento políticopedagógico implica a ampliação e reestruturação das escolas públicas, mediante a instalação de quadras poliesportivas e espaços culturais como auditórios e bibliotecas. (SANDER, 2015, p. 20).

Partindo das concepções destes dois autores acima citados que enfatizam a necessidade de investimentos e aperfeiçoamento nas áreas física, material, humana e profissional, e, trazendo o foco para a escola in lócus, além dos desafios citados, que possuem os seus desdobramentos em relação a material didático, alimentação, acréscimo de quantitativo e especializações de recursos humanos, entre outros, podemos ainda citar, de acordo com a vivência na escola in lócus, como desafios constantes:

a) A ausência da família, como principal responsável pela formação do cidadão, que necessita participar democraticamente do dia-a-dia da escola;

b) O diferencial entre o funcionamento das escolas de ensino fundamental em tempo regular e esta nova realidade no ensino médio;

c) A desestruturação dos valores éticos, morais e religiosos, que juntos, todos esses fatores levam às dificuldades de adaptação e relacionamento, de conscientização e formação crítico-construtiva, de autoafirmação, o que torna mais trabalhoso e difícil o papel social da escola;

d) A estrutura física, manutenção e a falta de investimento em recursos físicos e humanos que favoreçam o processo do ensinar e do aprender. 
Todos esses pontos incidem em um dos maiores desafios no decorrer dos anos que é o de superar as metas estipuladas anualmente, no Índice de Desenvolvimento da Educação de Pernambuco (IDEPE), fato que ainda gera a concorrência entre muitas instituições, descaracterizando uma das funções da educação, que é a de humanização.

\section{O percurso metodológico da pesquisa}

Este trabalho foi realizado inicialmente a partir do levantamento bibliográfico, baseado em autores como Gadotti (2016), Costa (2008), Delors (2010). Foram realizadas ainda observações na escola lócus da pesquisa, bem como questionário com membros da comunidade escolar e representantes da Gerência Regional de Educação de Pernambuco (GRE), para o levantamento, análise e consolidação de resultados que levassem ao resultado deste estudo. As Gerências Regionais de Educação integram a estrutura básica da Secretaria de Educação, distribuídas em regiões geográficas estratégicas, tendo, entre outras atribuições, que exercer ações de supervisão técnica, orientação normativa e de articulação e integração, tendo em vista a melhoria da qualidade do ensino.

O primeiro passo, após o estudo de teóricos acerca do tema, foi a observação do ambiente escolar, seu funcionamento, as atividades realizadas no dia a dia e a vivência dos estudantes com tudo e com todos.

A pesquisa teve uma abordagem qualitativa, pois, de acordo com Gil (2014, p. 42), “os métodos qualitativos são empregados através das pesquisas do tipo exploratório", que têm como objetivo proporcionar maior familiaridade com o problema, com vistas a torná-lo mais explícito ou a construir hipóteses e também porque é uma pesquisa que envolve: levantamento de bibliografia correlata, opiniões de pessoas entrevistadas sobre suas vivências junto ao problema pesquisado, além de exemplos analisados.

Partindo deste princípio, iniciamos este trabalho apresentando uma abordagem científica sobre o tema principal: escolas de ensino médio em tempo integral, utilizando referências de vários autores, abrangendo uma retrospectiva da implantação e funcionamento da escola, até a aplicação, análise e apresentação dos resultados do questionário com o grupo focal com integrantes da escola lócus da pesquisa. 
Optou-se pela metodologia da pesquisa-ação que segundo, Thiollent (2016, p. 36), este percurso metodológico pressupõe uma concepção de ação, que "requer, no mínimo, a definição de vários elementos: um agente (ou ator), um objeto sobre o qual se aplica a ação, um evento ou ato, um objetivo, um ou vários meios, um campo ou domínio delimitado".

Através deste tipo de pesquisa, aplicamos um questionário com agentes que compõem a comunidade educativa, como: professores, funcionários, estudantes, ex-estudantes, familiares, representante da gerência regional e parceiros da escola, analisar no contexto escolar, a fala de cada um dos sujeitos da pesquisa. Buscou-se, não somente apresentar suas respostas, mas relacioná-las ao teor desta pesquisa, que se refere especificamente à função social desta escola de ensino médio em tempo integral, seus desafios e sua contribuição na educação da cidade. Ao todo, foram 14 questionários, aplicados, sendo, 3 funcionários, 3 mães, 3 estudantes, 1 professor, 1 representante da GRE, 1 nutricionista da Secretaria de Educação e 2 ex-alunos.

Tivemos como lócus da pesquisa a Escola de Referência em Ensino Médio Maria Natalícia Figueiroa da Silva (ERNAF), situada à Vila da Cohab II, área suburbana do município de Surubim, agreste setentrional de Pernambuco. A ERNAF, como é conhecida foi transformada em EREM no ano de 2008, tendo sido pioneira entre as demais escolas de referência em ensino médio de Pernambuco e única no município à época.

Em 2018, no período da pesquisa, a escola funcionava com oito turmas de ensino médio no horário de $7 \mathrm{~h} 20$ as $16 \mathrm{~h} 50$, diariamente. Contava ainda com um quantitativo de 09 (nove) professores ligados ao Programa de Educação Integral, da Secretaria Executiva de Educação Profissional de Pernambuco, 04 (quatro) professores efetivos, não ligados ao Programa e 07 (sete) professores contratados por processo seletivo da Secretaria de Educação e Esportes, 03 (três) funcionários administrativos e 07 (sete) terceirizados.

A equipe gestora era composta por: uma gestora, um assistente de gestão, uma secretária, uma educadora de apoio. A equipe técnico-administrativa contava com uma coordenadora de biblioteca e uma analista em gestão educacional.

Os estudantes totalizavam 296, distribuídos entre os três primeiros anos, três segundos e dois terceiros anos. A referida instituição encontra-se jurisdicionada à Gerência Regional de Educação

\section{plurais}


(GRE) Vale do Capibaribe, Secretaria Executiva de Educação Profissional (SEEP) e da Secretaria de Educação e Esportes (SEE) de Pernambuco. Foram contemplados para a pesquisa, representantes de professores, funcionários, estudantes, ex-estudantes e familiares que formaram o grupo focal para coleta de dados que serviram de base para análise e concretização deste trabalho.

A coleta de dados foi feita por meio da análise de conteúdo (BARDIN, 2015). Um número significativo de autores de livros, artigos e dissertações foram pesquisados para a tomada de conhecimento acerca da implantação, funcionamento e resultados da escola de ensino médio em tempo integral no estado de Pernambuco. Bem como foram apresentados dados bibliográficos que evidenciam a implantação, funcionamento e resultados da ERNAF.

Para retratar o funcionamento, os desafios e resultados da ERNAF na história da educação de nossa comunidade, inicialmente foi aplicado um questionário semiestruturado com o grupo focal formado por representantes da nossa regional de educação, de funcionários, professores e colaboradores da escola, pais, estudantes e ex-alunos, com o intuito de obter dados capazes de direcionar as próximas etapas da pesquisa. Ou seja, qual o diferencial que podemos evidenciar no funcionamento da escola em tempo integral e como ela se revela na qualidade de vida do estudante desta escola e sua formação integral.

O questionário, segundo Gil (1999, p.128), pode ser definido "como a técnica de investigação composta por um número mais ou menos elevado de questões apresentadas por escrito às pessoas, tendo por objetivo o conhecimento de opiniões, crenças, sentimentos, interesses, expectativas, situações vivenciadas etc."

Este é o motivo pelo qual optamos pela aplicação do questionário com grupo focal da comunidade educativa: a coleta de informações oriundas de dados amostrais a partir da vivência de situações e experiências que nos permitiu coletar informações da realidade para a análise e conclusão.

Através do questionário, abordamos de início as seguintes questões: Qual a importância da escola em tempo integral para a educação do nosso município, do nosso estado, do nosso país? Quais as principais diferenças entre o ensino da escola regular e o da escola em tempo integral? Quais as principais vantagens que podemos destacar no trabalho desenvolvido pela ERNAF? 
Quais as principais dificuldades e desafios encontrados pela ERNAF? Como se dá a contribuição do trabalho desenvolvido pela ERNAF para o desenvolvimento integral do ser nas suas dimensões: afetiva, cognitiva, espiritual e de corporeidade?

Partindo desses questionamentos apresentamos a função social da ERNAF, seus desafios e contribuições para a educação interdimensional do ser, uma educação que faz a diferença, consolidamos, assim, a prática construtiva e mediadora deste trabalho até seu desfecho.

Como funcionalidade foi analisada a organização da instituição enquanto horário, carga horária, recursos humanos, projetos, entre outros dados encontrados no Projeto Político Pedagógico (PPP) da própria escola, bem como a filosofia norteadora.

Os desafios foram representados especificamente através da questão da adaptação dos estudantes em relação ao horário, relacionamento, processo avaliativo, espaço físico, recursos humanos e materiais, superação das metas e subsídios para o funcionamento e bons resultados através de uma educação de qualidade.

Os resultados foram retratados através dos índices de crescimento nas avaliações internas e externas durante a última década, encontrados em sites do MEC, Secretaria de Educação, entre outros. Os resultados para os estudantes e sua vida em sociedade, as contribuições dessa escola, foram relatados na fala dos sujeitos participantes do grupo focal questionadas: representantes da regional, de funcionários, professores, estudantes, ex-estudantes, colaboradores da escola.

Uma vez pesquisado, o material informativo foi analisado pelo grupo focal e serviu de subsídio para a organização do trabalho de análise de conteúdo propriamente dito, contemplando basicamente os seguintes tópicos: relevância das escolas em tempo integral para a educação; diferencial das escolas regulares e das escolas em tempo integral no estado de Pernambuco; benefícios destacados no trabalho desenvolvido pela escola pesquisada; principais desafios da escola in lócus; contribuição da escola in lócus no desenvolvimento integral de seus estudantes.

Como se refere Bardin (2015) em relação à análise de conteúdo, esta consiste de um conjunto de técnicas que se utiliza de procedimentos sistemáticos e objetivos de descrição do conteúdo das mensagens contidas nas comunicações que serão analisadas. A inferência de conhecimentos ligados às condições de produção ou de recepção retrata a intenção da análise de conteúdo.

\section{plurais}


De acordo com esta concepção, a análise de dados de certa forma se configura na interpretação de respostas obtidas através das respostas contidas no(s) instrumento(s) da coleta destes dados. Estas são uma representação da realidade experimentada pelos sujeitos questionados, e representam ação imprescindível no resultado de trabalhos científicos, baseados na pesquisa ação qualitativa.

Sendo assim, pelo teor deste trabalho, seus objetivos e objeto de estudo, tornou-se imprescindível a explanação, na íntegra, das respostas obtidas no questionário aplicado ao grupo focal e a análise realizada pela autora, que por possuir contato direto e constante com a realidade da escola, facilita a interpretação e a discussão desses resultados.

\section{Resultados qualitativos e quantitativos em uma escola integral: nossos achados por meio da Pedagogia de projetos.}

Os projetos desenvolvidos na escola precisam conduzir o estudante em um processo que envolva produção, questionamentos e o hábito de pesquisar. Na pedagogia de projetos, estas atitudes são ainda complementadas pela criação de relações, o incentivo a novas investigações, compreensões e modos de reconstruir a informação (PRADO, 2003).

Para esta autora, os projetos desenvolvidos de maneira articulada, que contam com o protagonismo de vários atores no processo educativo, são de grande importância, pois, articulam o projeto da gestão escolar com o que o professor desenvolve em sala de aula, propiciando o desenvolvimento de projetos de interesse comum (IDEM). Diante do exposto é relevante informar que a ERNAF lócus da pesquisa, desenvolve ações através da Pedagogia de Projetos, que vem dialogar com a realidade da escola e seus partícipes.

Durante o período da pesquisa, foi possível observar a rotina da escola e as variadas ações pedagógicas desenvolvidas ao longo do ano. São atividades de acolhida dos novos estudantes, de dias festivos, como o carnaval, dia dos namorados, festa junina e Natal. Além de outras de cunho pedagógico, a exemplo de monitoria estudantil, gestão participativa e compartilhamento de vivências em sala de aula. As atividades mencionadas são assim intituladas: ERNAFOLIA, ERNAMORO, Projeto Show de Talentos, ERNAFORRÓ, Projeto Afro-indígena na escola, ERNAFELIZ, Desfile Cívico e outros. 
Para fins deste estudo, nos deteremos em um destes projetos desenvolvidos na escola: o Projeto Gestão Participativa.

A partir do mês de março do ano de 2018, a equipe gestora da ERNAF deu início ao Projeto Gestão Participativa, caracterizado por encontros bimestrais entre a equipe gestora, diretoria do grêmio estudantil, Nelson Barbosa, e estudantes representantes de todas as turmas. Este projeto tem por objetivo principal, fortalecer o trabalho da escola com foco na gestão democrática de forma a proporcionar aos estudantes um sentimento de pertencimento, cada vez mais aguçado, levando-os a perceberem-se como o centro da função social da escola, com seus direitos e deveres, na construção de uma educação de qualidade e fortalecimento da cidadania.

Dentre as atividades sugeridas e postas em prática, durante a vivência desse projeto, podemos citar: melhor conservação do patrimônio escolar, momentos de cultura e lazer no ambiente escolar, apoio a estudantes novatos, com dificuldades diversas.

O projeto acontece com registro em ata, avaliação do funcionamento do bimestre e replanejamento das atividades vivenciadas e sugeridas. Tem por base o projeto político pedagógico da escola, que é desenvolvido no dia a dia da mesma, levando em consideração a realidade e necessidades da comunidade escolar, bem como os interesses dos estudantes dentro da proposta de ensino-aprendizagem, sugerida pela Secretaria de Educação do Estado, com embasamento legal nos documentos orientadores da educação nacional. Esse encontro também avalia o funcionamento das atividades desenvolvidas em cada bimestre letivo, detectando problemas e dificuldades em todos os âmbitos: pedagógico, administrativo, social, visando um melhor resultado dos objetivos propostos, listando sugestões de otimização do planejamento escolar.

É importante ressaltar que este trabalho acaba por oportunizar a criação e implantação de novos projetos e planos de ação a poderão ser desenvolvidos por todos os componentes da escola: estudantes professores, funcionários e familiares e vem apresentando resultados positivos que fazem a diferença na história de nossa instituição.

\footnotetext{
plurais 


\section{Análises e resultados: uma trajetória a ser compartilhada}

Os resultados qualitativos que podemos destacar como relevantes para os estudantes e sua vida em sociedade, assim como para seus familiares e as contribuições dessa escola, foram relatados, através do questionário aplicado com representantes desta comunidade educativa. A importância de detalhar neste artigo, o instrumento de coleta de dados, é evidenciar o grau de satisfação da comunidade escolar, o que corrobora o objetivo da pesquisa.

O questionário aplicado foi precedido por várias etapas, a fim de que sua compreensão fosse a melhor possível por parte dos entrevistados, garantindo a fidedignidade das informações coletadas. A seguir, podemos conhecer as fases para a sua aplicação.

Quadro 1 - Fases do questionário e procedimentos

\begin{tabular}{|l|l|}
\hline \multicolumn{1}{|c|}{ FASES } & \multicolumn{1}{c|}{ PROCEDIMENTOS } \\
\hline Convite & É solicitado aos sujeitos que analisem o tema de pesquisa \\
\hline Enunciado & $\begin{array}{l}\text { É pedido aos entrevistados que respondam uma ficha padrão, questionamentos a } \\
\text { respeito dodia-a-dia na escola em tempo integral }\end{array}$ \\
\hline Averiguação & Pede-se aos entrevistados que exemplifiquem as respostas \\
\hline Questionário & $\begin{array}{l}\text { Solicita-se aos membros do grupo focal que respondam consistentemente aos questio- } \\
\text { namentos requisitados neste documento }\end{array}$ \\
\hline
\end{tabular}

Fonte: Autoras (2018)

Em relação à análise dos resultados do questionário, retomamos que a primeira pergunta se refere a importância da escola em tempo integral para a educação. A segunda pergunta refere-se às principais diferenças entre o ensino da escola regular e o da escola em tempo integral. A terceira: vantagens e/ou benefícios do trabalho da ERNAF. A quarta: dificuldades e/ou desafios do trabalho da ERNAF. A quinta pergunta refere-se a como o trabalho da ERNAF favorece o desempenho do (a) estudante na sua dimensão integral: afetiva, cognitiva, espiritual e corpórea. E por última, solicita uma opinião a respeito da importância do trabalho da escola em tempo integral, mais especificamente da ERNAF.

O levantamento de opiniões comuns entre os entrevistados, em cada item do questionário. Finalizada a etapa de coleta de informações, através dos questionários, procedeu-se ao 
processamento das respostas, com apoio do grupo focal. Assim, para cada pergunta, se elegeram as principais contribuições dos sujeitos da pesquisa. A fim de facilitar a referência aos integrantes do grupo focal, foi convencionado um código: Funcionário (F); Mãe (M); Estudante (E); Professor (P). A seguir as questões e as vozes que não calam:

Quando questionados sobre qual a importância da escola em tempo integral para a educação em seu município, em seu estado e em nível de Brasil? Obtivemos as seguintes respostas, conforme análise: F1 - destaca a disponibilidade de tempo, assim como F2 e M1, que apontam a oportunidade de estar por mais tempo se dedicando ao estudo. E1 e E2 veem vantagem em se preparar para os vestibulares. F1, F2 e E3 destacam a importância do aspecto relacional no aprender a conviver e formação dos jovens para o dia-a-dia. F1 e F2 concordam que o estudante não é só desenvolvido no aspecto cognitivo.

Sobre quais as principais diferenças que você elenca entre o ensino da escola regular e o da escola em tempo integral? Responderam que: F1 e E1 concordam que a EREM prepara para a vida, também emocionalmente. M1 e M2 afirmam que prepara a superar obstáculos e ser mais seguros de si.

No que concerne quais as vantagens elou beneficios que você destaca no trabalho educativo desenvolvido pela ERNAF? Afirmaram que: F2 e F3 afirmam que a escola sempre busca integrar o estudante com a sociedade e mercado de trabalho. M3 e E1 apontam para o benefício do protagonismo juvenil.

Quando questionados sobre as dificuldades e/ou desafios? Tivemos os seguintes achados: F1, M3 e E1 se referem à dificuldade e o cansaço na fase de adaptação ao horário integral. F1 e F2 se ressentem da ausência dos pais no acompanhamento do aluno. Já M1 e P1 destacam as dificuldades de estrutura física da escola.

Ao serem indagados sobre como a ERNAF tem favorecido o desenvolvimento integral do ser nas suas dimensões: afetiva, cognitiva, espiritual e de corporeidade? Responderam que: F1 e F2 afirmam que tem favorecido através do resgate de valores, que torna o estudante sujeito da ação, um protagonista. E2 e E3 acrescentam que isto ocorre com o desenvolvimento integral do educando.

\footnotetext{
plurais 
Ao solicitarmos em linhas gerais, deixe sua opinião a respeito da ERNAF enquanto instituição de ensino que desenvolve um trabalho diferenciado na educação do jovem surubinense? Para F1 e P1 o que há de negativo é o difícil acesso, estrutura física precária, déficit de funcionários e recursos financeiros, F3 e E1 destacam ainda que não é uma escola perfeita, embora seja eficiente, e que deve melhorar em alguns aspectos. No entanto, F2, F3, E2 e E3 destacam que a ERNAF é referência no município e região, que busca o direito do aluno a uma educação de qualidade, sendo uma escola de grande diferença na região.

De acordo com os achados na análise dos dados, a pesquisa conseguiu obter do grupo focal, um panorama coerente do que foi tratado neste estudo, pontuando os desafios, possibilidades e conquistas com as ações de cunho pedagógico e social desenvolvidos pela escola, assim atendendo aos objetivos propostos por este estudo e o mais relevante a descrição do funcionamento e organização da ERNAF. A importância da educação integral, em relação à modalidade regular, foi destacada nas falas dos sujeitos, que enalteceram os esforços da escola no trabalho educativo.

Em relação as vantagens/benefícios que se destacam no trabalho educativo desenvolvido pela ERNAF, obtivemos as respostas positivas em relação à qualidade, cultivo de valores e favorecimento à socialização através dos relacionamentos. Ainda se percebeu que este modelo de escola facilita a inserção do jovem no mercado de trabalho por desenvolver mais intensamente suas habilidades, preparando-os com mais tempo e oportunidades para as avaliações internas e externas.

Importa destacar as vivências das aulas de Estudo Dirigidas, Monitoria Estudantil e Reforço. O protagonismo juvenil se evidencia fortemente através de um variado quantitativo de projetos vivenciados na comunidade. A participação da família possui caráter prioritário para o bom desempenho dos estudantes através dos momentos disponibilizados para tal. É uma escola cujos profissionais trabalham com muito compromisso, profissionalismo, dedicação, disponibilidade para atender os estudantes em suas necessidades, valorizam o trabalho em equipe, com foco e organização.

Estas atitudes possuem relevância também na Educação Interdimensional, que prepara os estudantes nas dimensões afetiva, cognitiva, corpórea e espiritual. Além disso, considera o ser, suas histórias, potencialidades, sua realidade. Os momentos de oração, reflexão e outras vivências, auxiliam bastante o estudante na fase em que se encontram. Ressalta aqui o reforço à vivência de

\section{plurais}


uma gestão ainda mais democrática e participativa a partir do ano de 2017, através da criação de novos projetos e renovação de alguns anteriores, no sentido de superar algumas dificuldades que vinham se intensificando na comunidade educativa.

\section{Considerações finais}

O objetivo deste artigo foi perceber, a partir da escuta da comunidade escolar, os impactos dos resultados obtidos por uma escola integral do município de Surubim. As questões abordadas: Como funciona esta escola em tempo integral? Quais os principais desafios encontrados no dia a dia desta escola? Quais os principais resultados do trabalho realizado por esta escola que fazem a diferença na vida da comunidade? Conseguiram dar conta de responder em relação ao funcionamento, organização, desafios e contribuições da ERNAF para o município de Surubim no estado de Pernambuco.

Assim, foi possível conhecermos de perto este funcionamento, acompanhando o trabalho diário e buscando a opinião de membros desta comunidade para também fundamentar nossos resultados. Vale salientar que, apesar de apresentarmos alguns dados estatísticos, numéricos, em relação aos resultados da ERNAF - como é conhecida a EREM supracitada, a abordagem da pesquisa foi de cunho qualitativo, pois, como afirma Minayo (2008), a análise dos dados acontece a partir da análise do material adquirido no trabalho de campo para a construção do trabalho científico.

Tomamos como tipo de pesquisa, a pesquisa-ação, por apresentar caráter participativo, impulso democrático e contribuição à mudança social, para a coleta dos dados, como instrumento de coleta de dados o questionário, com diversos sujeitos envolvidos, direta, ou indiretamente, no trabalho desenvolvido na escola. As respostas foram a base de dados para a análise dos resultados, que compõe as categorias: funcionamento, desafios e resultados da escola em tempo integral.

Foram elementos importantes para uma apreciação mais consistente deste estudo, por não nos determos apenas nos resultados propriamente ditos, porém, mais especificamente no funcionamento, o que representa o dia-a-dia da escola. Para chegar a estes resultados diferenciados na comunidade, os estudantes receberam uma educação também distinta, durante sua passagem por esta etapa da educação básica na escola analisada, as opiniões dos sujeitos foram praticamente unânimes.

\section{plurais}

Salvador, v.5, n.1 p.220-240, jan/abr. 2020 
Espera-se que os relatos exitosos, descritos neste estudo, contribuam para fomentar o interesse em futuras pesquisas acerca dos benefícios da Educação Interdimensional, inserida em uma escola de horário integral. Do mesmo modo se suscita a expectativa de ações governamentais para mitigar as limitações financeiras e estruturais, elencadas ao longo da pesquisa, além de políticas públicas que possam contemplar a totalidade das escolas públicas do estado, que carecem de melhor infraestrutura para atender seus estudantes.

\section{REFERÊNCIAS}

BARDIN, Laurence. Análise de conteúdo. Lisboa: Edições 70. 2015 (Obra original publicada em 1977).

COSTA, Antônio Carlos Gomes da. Pedagogia da Presença: da solidão ao encontro. 2. ed. Belo Horizonte: Modus Fasciendi, 2001.

COSTA, Antônio Carlos Gomes da. Educação: coleção valores. São Paulo: Canção Nova, 2008. DELORS, Jaques. Educação, um tesouro a descobrir. Brasília: UNESCO, 2010.

GADOTTI, Moacir. Educação Integral no Brasil: inovações em processo. São Paulo: Instituto Paulo Freire, 2016.

GIL, Antonio Carlos. A Introdução a Metodologia Científica. São Paulo: Ática, 2014.

KRAWCZYK, Nora. Políticas para o ensino médio e seu potencial inclusivo. $36^{\mathrm{a}}$ Reunião Nacional da Anped. Goiânia, 2013, p. 1-17. Disponível em: http://36reuniao.anped.org.br/pdfs sessoes_especiais/se_05_norakrawcyk_gt05.pdf. Acesso em: 18 mar. 2018.

MANCINI, Ana Maria Penalva. Modos de subjetivação: jovens na escola. In: MORGADO, Maria Aparecida e MOTTA, Manoel Francisco de Vasconcelos (Orgs). Juventude de classe média e educação: cenários, cenas e sinais. Brasília: Líber Livro Editora, 2006.

MINAYO, Maria Cecília de S. Pesquisa Social - Teoria, método e criatividade. Petrópolis, RJ: Vozes, 2008.

PEREIRA, Cláudia Justus Torres. A Formação do Professor Alfabetizador: desafios e possibilidades na construção da prática docente. 2011. 130 fls. Dissertação (Mestrado em Educação) - Fundação Universidade Federal de Rondônia. Porto Velho, RO, 2011. 
PIAGET, Jean. Para onde vai a educação. Rio de Janeiro: José Olímpio, 2007.

PRADO, Maria Elisabette Brisola Brito Prado. Pedagogia de Projetos. Série Pedagogia de Projetos e Integração de Mídias - Programa Salto para o Futuro, Setembro, 2003.

RÖHR, Ferdinand. Educação e espiritualidade: contribuição para uma compreensão multidimensional da realidade, do homem e da educação. São Paulo: Mercado Letras, 2013.

SANDER, Benno. A integração da cultura ao mundo da ciência e do trabalho. São Paulo: Atlas, 2015.

SANTOS, Lucíola Licínio de Castro Paixão; OLIVEIRA, Nilza Helena. O coordenador pedagógico no contexto de gestão democrática da escola. In: XXIII Simpósio Brasileiro/V Congresso Luso-Brasileiro/I Colóquio Ibero-Americano de Política e Administração da Educação: Por uma escola de qualidade para todos. Formação. Financiamento e gestão da Educação, 2007, Porto Alegre: Cadernos ANPAE. ANAPAE/UFRGS, 2007, p. 1 - 14.

THIOLLENT, Michel. Pesquisa-ação nas organizações. São Paulo: Atlas, 2016.

Recebido em: 07 de abril de 2020.

Avaliado em: 17 de maio de 2020.

Esta obra está licenciada com uma Licença Creative Commons Atribuição 4.0 Internacional. 